Reproduction

\section{Widespread cloning in echinoderm larvae}

sexual reproduction by free-living invertebrate larvae is a rare and enigmatic phenomenon and, although it is known to occur in sea stars ${ }^{1-4}$ and brittle stars $^{5,6}$, it has not been detected in other echinoderms despite more than a century of intensive study ${ }^{6,7}$. Here we describe spontaneous larval cloning in three species from two more echinoderm classes: a sea cucumber (Holothuroidea), a sand dollar and a sea urchin (Echinoidea). Larval cloning may therefore be an ancient ability of echinoderms and possibly of deuterostomes - the group that includes echinoderms, acorn worms, sea squirts and vertebrates.

To confirm that genuine cloning was occurring, we reared cloning larvae and separated clones individually (Fig. 1, legend). Although most sea cucumber larvae metamorphosed normally after a month, 5 of 41 $(12.2 \%)$ free-swimming doliolaria larvae were half the length of their siblings and had a constriction around the penultimate ciliary band. These buds retained a ciliary band and were still attached by a thin tether into the benthic pentacula stage $12 \mathrm{~h}$ later (Fig. 1a). Eventually, after separation, buds developed into normal auricularia larvae with a juvenile rudiment (Fig. 1b).

Most sand dollar larvae metamorphosed within 7 weeks, but 6 of 170 (3.5\%) formed a hollow bud near the future juvenile mouth (results not shown). Once separated, the evenly ciliated buds developed into an almost solid gastrula with bilateral spicules. Within two days, a tripartite gut and further skeletal spicules formed, and the clones began to feed.

After 4 weeks, nearly $5 \%$ of sea urchin larvae $(n>500)$ showed constrictions at their posterior end (Fig. 1c). These eventually yielded uniformly ciliated buds that began feeding within four days, developed paired skeletal rods within a week, and acquired a normal larval form within two weeks. Juvenile rudiments began to form within three weeks (Fig. 1d), accompanied by further larval arms.

Larval cloning is therefore known to occur in all classes except crinoids (feather stars and sea lilies), supporting an earlier conjecture that it might be an ancestral ability of echinoderms ${ }^{8}$. The mechanisms by which this cloning occurs, however, are unexpectedly diverse. First, clones may arise from various larval body regions, including arms (sea stars ${ }^{1-4}$, brittle stars ${ }^{5}$ ), the oral hood (sea stars ${ }^{2-4}$ ), the posterior end (sea stars ${ }^{3}$, sea cucumbers (Fig. 1a), sea urchins (Fig. 1c)) and the lateral body wall (sea stars ${ }^{2}$, sand dollars (our results, not shown)). Second, the
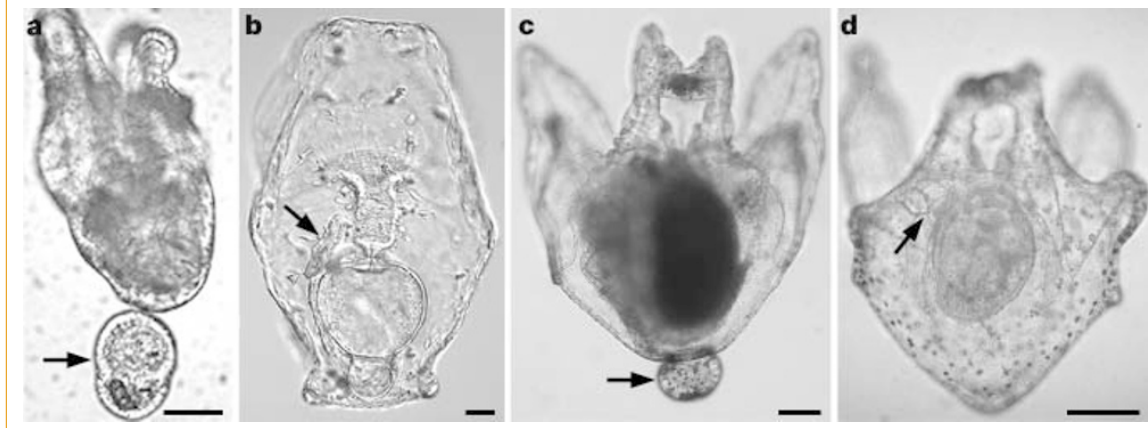

Figure 1 Asexual budding by echinoderm larvae. a, Sea cucumber (Parastichopus californicus; Holothuroidea; Aspidochirotida) early pentacula with clone attached at posterior end (arrowhead). b, Sea cucumber 18 days after separation as a complete auricularia larva, with juvenile rudiment (arrow). c, Sea urchin (Strongylocentrotus purpuratus; Echinoidea, Echinacea) larva with a clone (arrow) constricting from the posterior end around the robust ciliary band. d, Sea urchin clone three weeks after separation, with early juvenile rudiment (arrow). Scale bars, $50 \mu \mathrm{m}$. Adult $P$. californicus were collected sub-tidally from San Juan Island, Washington, and gametes were collected by dissection. Larvae were maintained at $11^{\circ} \mathrm{C}$ under natural lighting in filtered sea water and were fed a red alga Rhodomonas salina, ad libitum. Adult S. purpuratus from Prasiola Point (Vancouver Island, Canada) were spawned by intracoelomic injection of $0.55 \mathrm{M}$ potassium chloride. Larvae were maintained in a 19-h light cycle at $14^{\circ} \mathrm{C}$ in pasteurized sea water and were fed $>10^{6}$ cells per $\mathrm{ml}$ of a golden brown alga Isochrysis galbana and $R$. salina; food and water were replaced every $72 \mathrm{~h}$. To monitor their development, cloning larvae and separated clones were isolated in 7-ml glass vials and cultured; most developed to metamorphosis. Cultures were deemed to be healthy as no larval tissue necrosis was seen. Further details are available from the authors.

developmental stage of clones at separation ranges from blastulae ${ }^{2}$ to fully formed lar$v^{3} e^{3}$. Third, some clones may not separate until after the primary larva has begun to metamorphose $^{5}$ (Fig. 1a). This indicates either that larval cloning evolved independently on several occasions or that its mechanisms have diverged widely from an ancestral mode.

Cloning can be surprisingly frequent: up to $12 \%$ in laboratory-reared sea cucumber larvae and $10-90 \%$ in samples of field-collected sea star larvae $e^{1,4}$. The fact that such a common phenomenon should have been overlooked in heavily studied organisms seems remarkable. Were preconceptions about 'normal' development so strong that cloning was simply dismissed as aberrant? From a theoretical perspective, larval cloning - particularly in sea urchins challenges a central tenet of the 'set-aside' cell theory ${ }^{9}$ because, contrary to prediction, larval body cells are not "essentially eutelic", but can differentiate into juvenile structures (Fig. 1b, d). Nevertheless, such cloning offers an opportunity to study the well-characterized developmental regulatory networks of sea urchins ${ }^{10}$ in a new ontogenetic context.

Larval cloning represents an intriguing new dimension to invertebrate life histories. The process confers three potential ecological advantages: increased fecundity under optimal growth conditions ${ }^{2,3}$, increased chances of settlement after a protracted larval life $e^{1,2,5}$, and recycling of otherwise discarded or reabsorbed larval tissue $^{5}$. Larval cloning may also be evolutionarily significant, for two reasons. First, clones may subsequently clone ${ }^{5}$, potentially leading to a new, entirely pelagic bauplan. Second, although it may be merely another idiosyncrasy of echinoderm development, larval cloning might also be more taxonomically widespread. As nearest relatives to the echinoderms ${ }^{11}$, acorn worms offer a critical test. If their tornaria larvae clone, then ancient deuterosomes may have had this ability.

Alexandra A. Eaves ${ }^{\star}$, A. Richard Palmer $\dagger$

${ }^{*}$ Physiology and Cell Biology Group, and

$\dagger$ Systematics and Evolution Group, Department of

Biological Sciences, University of Alberta,

Edmonton, Alberta T6G 2E9, Canada, and

Bamfield Marine Sciences Centre, Bamfield, British

Columbia VOR 1B0, Canada

e-mail: aeaves@ualberta.ca

1. Bosh, I., Rivkin, R. B. \& Alexander, S. P. Nature 337, 169-170 (1989).

2. Jaeckle, W. B. Biol. Bull. 186, 62-71 (1994).

3. Vickery, M. S. \& McClintock, J. B. Biol. Bull. 199, 298-304 (2000).

4. Knott, K. E., Balser, E. J., Jaeckle, W. B. \& Wray, G. A. Biol. Bull. 204, 246-255 (2003)

5. Balser, E. J. Biol. Bull. 194, 187-193 (1998).

6. Mortensen, T. Studies of the Development and Larval Forms of Echinoderms (Gad, Copenhagen, 1921).

7. MacBride, E. W. Nature 108, 529-530 (1921)

8. Lacalli, T. C. Invertebr. Biol. 119, 234-241 (2000).

9. Davidson, E. H., Cameron, R. A. \& Ransick, A. Development 125, 3269-3290 (1998)

10. Davidson, E. H. et al. Science 295, 1669-1678 (2002).

11. Cameron, C. B., Garey, J. R. \& Swalla, B. J. Proc. Natl Acad. Sci. USA 97, 4469-4474 (2000).

Competing financial interests: declared none.

brief communications is intended to provide a forum for brief, topical reports of general scientific interest and for technical discussion of recently published material of particular interest to non-specialist readers (communications arising). Priority will be given to contributions that have fewer than 500 words, 10 references and only one figure. Detailed guidelines are available on Nature's website (www.nature.com/nature). 